Original Article

\title{
Lifetime use of complementary and alternative medicine therapies among community-dwelling older people in Japan
}

\author{
Yosuke Shibata, $\mathrm{PhD}^{1)^{*}}$, Mieko Nakamura, MD, PhD ${ }^{1)}$, Hideko Nakamura, $\mathrm{PhD}^{2)}$, \\ EISAKu OKada, $\mathrm{PhD}^{1)}$, Toshiyuki Ojima, MD, $\mathrm{PhD}^{1)}$ \\ 1) Department of Community Health and Preventive Medicine, Hamamatsu University School of \\ Medicine: 1-20-1 Handayama, Higashi-ku, Hamamatsu, Shizuoka 431-3192, Japan \\ 2) School of Nursing, Seirei Christopher University, Japan
}

\begin{abstract}
Purpose] Three complementary and alternative medicine (CAM) therapies: "Judo therapy", "acupuncture and moxibustion", and "Japanese traditional massage and finger pressure" have been partially covered by the national health insurance in Japan. The lifetime prevalence of the use of these CAM therapies is not well known. The aim of the present study was to report the prevalence of the lifetime use of these CAM therapies. [Participants and Methods] We conducted a mailed self-administered questionnaire survey among community-dwelling older people in Japan in 2015. They were asked whether they had undergone any treatments with the 3 CAM therapies. The answers obtained were classified into 3 categories: current, ever, or never. We defined lifetime prevalence as the proportion of individuals who are currently using or have ever used any of these 3 therapies in the population. [Results] Overall, we approached 1051 individuals and 983 agreed to participate. Lifetime prevalence of Judo therapy, acupuncture and moxibustion, and Japanese traditional massage and finger pressure use was $28.0 \%, 17.8 \%$ and $15.8 \%$, respectively, among males, and $44.5 \%, 18.4 \%$, and $27.3 \%$, respectively, among females. [Conclusion] These results showed that not only Western medicine but also CAM therapies are common among older people in Japan. Key words: Judo therapy, Acupuncture and moxibustion, Japanese traditional massage and finger pressure
\end{abstract}

(This article was submitted Feb. 18, 2020, and was accepted Apr. 3, 2020)

\section{INTRODUCTION}

Complementary and alternative medicine (CAM) therapies have long been used for treatment of several diseases and disorders ${ }^{1,2)}$. Many studies reported the prevalence of such CAM therapy use ${ }^{3-11)}$. For example, the last 12-month prevalence of any CAM therapy use was $88 \%$ in the US ${ }^{8)}, 74.8 \%$ in 2006 and $71.3 \%$ in 2011 in South Korea ${ }^{3,9)}, 55.7 \%$ in Puerto Rico ${ }^{10)}$, $38.2 \%$ in Qatar $^{6}$ ) $26.3 \%$ in the $\mathrm{UK}^{7)}$, and $21.2 \%$ in Australia ${ }^{11)}$. In this way, the prevalence of CAM therapy use has varied by country. To obtain the exact prevalence of CAM therapy use, descriptive studies are needed in each country.

CAM therapies can be categorized into 2 major categories; natural products or mind and body practices ${ }^{12)}$."Judo therapy," "acupuncture and moxibustion," and "Japanese traditional massage and finger pressure" belong to mind and body practices. These 3 CAM therapies have been partially covered by national health insurance in Japan. Judo therapists were called bonesetters, and the used manipulation to treat bone fractures, dislocation and soft tissue damage. Treatments for only these injuries have been covered by national health insurance in Japan. Facilities providing Judo therapy number about 46,000 in Japan $^{13)}$. Acupuncture and moxibustion therapies are also common in Japan ${ }^{14)}$. Treatments of acupuncture and moxibustion practitioners for neuralgia, rheumatoid arthritis, cervico-brachial syndrome, frozen shoulder, low back pain and traumatic cervical syndrome are also covered by national health insurance in Japan. Japanese traditional massage and finger pressure

* Corresponding author. Yosuke Shibata (E-mail: shibata-yosuke@umin.ac.jp)

(C2020 The Society of Physical Therapy Science. Published by IPEC Inc.

(c) (1) $\odot$ This is an open-access article distributed under the terms of the Creative Commons Attribution Non-Commercial No Derivatives cc) 
(therapeutic touch), Anma-Massage-Shiatsu in Japanese, is one of the most popular types of CAM therapy in Japan ${ }^{15)}$. Practitioners use touch and manual therapies ${ }^{16}$. Treatment with Japanese traditional massage and finger pressure for muscle paralysis and arthrogryposis has been covered by national health insurance. There are now about 25,000 facilities in Japan providing acupuncture and moxibustion, while 19,000 specialize in Japanese traditional massage and finger pressure ${ }^{13)}$. Practitioners of these 3 CAM therapies receive education of over 3 years and must pass a national examination. In 2017, National medical care expenditure for these 3 CAM therapies was about 540 billion yen in Japan ${ }^{17}$. It is important to decrease the national medical care expenditure in Japan. However, the status of use of the 3 CAM therapies has not been reported, not to mention their prevalence. The aim of the present study is thus to determine the lifetime prevalence of the use of these 3 CAM therapies.

\section{PARTICIPANTS AND METHODS}

This cross-sectional study was conducted in November 2015 in a city in Shizuoka Prefecture in Japan. The city was suburban and older people comprised one-fourth of the population. A survey was conducted with the cooperation of a city office. A self-administered questionnaire was mailed out for assessment of health status and social activity among communitydwelling older people. One thousand fifty-one individuals were randomly selected in their 70s and 80 s who were not certified care recipients. Family members completed the questionnaire for those who needed assistance.

Information was obtained by a self-administered survey on the use of judo therapy, acupuncture and moxibustion, and Japanese traditional massage and finger pressure. Answers were obtained from 3 categories; current, ever or never use. Japanese traditional massage and finger pressure, chiropractic and seitai were combined in one category in the questionnaire. Data on weight $(\mathrm{kg})$, height $(\mathrm{cm})$, education ( $<$ high school, or $\geq$ high school), living status (alone, or not), marital status (married or not), self-rated health (good, relatively good, ordinary, relatively poor, or poor) and medical histories of stroke, heart attack, cancer and diabetes mellitus (yes, or no) were also obtained. Body mass index (BMI) was calculated as weight divided by square of height $\left(\mathrm{kg} / \mathrm{m}^{2}\right)$. Divorced and widowed persons were included in the non-married status. Self-rated health was defined as good (good and relatively good), ordinary (ordinary) and poor (relatively poor and poor). The lifetime prevalence of CAM therapies was defined as the proportion of total current and ever user in the surveyed population.

$\chi^{2}$ test or Fisher's exact test for small samples was used for comparison of proportion for variables. All statistics were performed using SPSS version 22.0 for Windows (IBM Japan Inc., Tokyo, Japan) with a significance level of $\mathrm{p}<0.05$.

The institutional review board of Hamamatsu University School of Medicine approved this study (E15-213). Informed consent was obtained from all participants.

\section{RESULTS}

Overall, 1,051 older people were approached and 983 agreed to participate in the study; the response rate was $93.5 \%$. Proportion of females was $70.7 \%$. Mean age was 78.4 years. Mean weight was 57.5 and $46.8 \mathrm{~kg}$, and mean height was 160.3 and $147.3 \mathrm{~cm}$ among males and females, respectively. Mean BMI was 22.4 and $21.6 \mathrm{~kg} / \mathrm{m}^{2}$, respectively, among males and females. Approximately $10 \%$ of participants were living alone and about $80 \%$ of them were in good and ordinary self-rated health (Table 1).

Lifetime prevalence of Judo therapy use was $28.0 \%$ and $44.5 \%$, respectively, in males and females. That of acupuncture and moxibustion use was $17.8 \%$ and $18.4 \%$, respectively, in males and females, and that of Japanese traditional massage and finger pressure was $15.8 \%$ and $27.3 \%$, respectively (Table 2). Lifetime prevalence of the use of any of the 3 CAM therapies was $42.9 \%$ and $57.6 \%$ among males and females, respectively.

\section{DISCUSSION}

The present study reported the lifetime prevalence of Judo therapies (males, 28.0\%; females, 44.5\%), acupuncture and moxibustion (males, 17.8\%; females, 18.4\%) and Japanese traditional massage and finger pressure use (males, 15.8\%; females, $27.3 \%$ ) among community-dwelling older people in Japan. It is the first study to report the prevalence of 3 CAM therapies, covered by national health insurance in Japan.

To our knowledge, this is the first study to show the lifetime prevalence of Judo therapy use. Most previous studies about Judo therapy have focused on practitioner aspects such as the number, distribution and techniques of Judo therapists ${ }^{18-20)}$. Additionally, most previous studies on the prevalence of Judo therapy use did not treat Judo therapy separate from other CAM therapies ${ }^{21)}$.

The lifetime prevalence of acupuncture and moxibustion was roughly less than $20 \%$ in the present study. Several earlier investigations showed a lifetime prevalence of acupuncture at $26 \%$ in Sweden ${ }^{22}$, $11 \%$ in Denmark and Norway ${ }^{22}$, and $7 \%$ in the $\mathrm{UK}^{23)}$, respectively. Several reports indicated that the prevalence of acupuncture was higher in Japan than Western countries $^{24,25)}$. Previous studies on the Japanese population reported that 12-month and lifetime prevalence of acupuncture were $14.1 \%$ and $25.4 \%$, respectively ${ }^{14,26}$. Our findings were consistent with previous studies, which reflected the influence of different culture. 
Table 1. Study characteristics

\begin{tabular}{|c|c|c|}
\hline & Male & Female \\
\hline $\mathrm{n}$ & 288 & 695 \\
\hline \multicolumn{3}{|l|}{ Age } \\
\hline 70-79 years & $199(69.1)$ & $424(61.0)$ \\
\hline $80-89$ years & 89 (30.9) & $271(39.0)$ \\
\hline \multicolumn{3}{|l|}{$\mathrm{BMI}^{\mathrm{a}}$} \\
\hline Normal & $217(80.4)$ & $480(75.9)$ \\
\hline Underweight & $17(6.3)$ & $84(13.3)$ \\
\hline Obesity & $36(13.3)$ & $68(10.8)$ \\
\hline \multicolumn{3}{|l|}{ Education } \\
\hline$<$ High school & $118(41.7)$ & $369(54.4)$ \\
\hline$\geq$ High school & $165(58.3)$ & 309 (45.6) \\
\hline \multicolumn{3}{|l|}{ Living } \\
\hline Not alone & $261(92.6)$ & $585(85.8)$ \\
\hline Alone & $21(7.4)$ & $97(14.2)$ \\
\hline \multicolumn{3}{|l|}{ Marital status } \\
\hline Not married ${ }^{b}$ & $50(17.8)$ & $374(56.0)$ \\
\hline Married & $231(82.2)$ & $294(44.0)$ \\
\hline \multicolumn{3}{|l|}{ Self-rated health ${ }^{\mathrm{c}}$} \\
\hline Good & $125(44.6)$ & $329(49.0)$ \\
\hline Ordinary & $100(35.7)$ & $200(29.8)$ \\
\hline Poor & 55 (19.6) & $142(21.2)$ \\
\hline \multicolumn{3}{|l|}{ Medical history } \\
\hline \multicolumn{3}{|l|}{ Stroke } \\
\hline No & 247 (93.9) & 579 (95.9) \\
\hline Yes & $16(6.1)$ & $25(4.1)$ \\
\hline \multicolumn{3}{|l|}{ Heart attack } \\
\hline No & $225(85.6)$ & $547(90.6)$ \\
\hline Yes & $38(14.4)$ & $57(9.4)$ \\
\hline \multicolumn{3}{|l|}{ Cancer } \\
\hline No & $250(95.1)$ & $587(97.2)$ \\
\hline Yes & $13(4.9)$ & $17(2.8)$ \\
\hline \multicolumn{3}{|c|}{ Diabetes mellitus } \\
\hline No & $232(88.2)$ & $537(88.9)$ \\
\hline Yes & $31(11.8)$ & $67(11.1)$ \\
\hline
\end{tabular}

BMI: body mass index.

Data are shown as a percentage in parentheses.

aUnderweight, normal and obesity defined as BMI $\leq 18.5,18.5-25.0$ and $25.0 \leq$, respectively.

${ }^{\mathrm{b}}$ Not married including divorced and widowed.

${ }^{c}$ Five categoris of answers were distinguished: good (good and relatively good), ordinary (ordinary) and poor (relatively poor and poor).

Table 2. Lifetime prevalence of 3 CAM therapies

\begin{tabular}{lcc}
\hline & Male & Female \\
\hline Judo therapy & & \\
$\quad$ Current & $9(8.4)$ & $36(14.2)$ \\
Ever & $21(19.6)$ & $77(30.3)$ \\
$\quad$ Never & $77(72.0)$ & $141(55.5)$ \\
Acupuncture and moxibustion & & \\
$\quad$ Current & $4(4.0)$ & $8(3.7)$ \\
Ever & $14(13.9)$ & $32(14.7)$ \\
Never & $83(82.2)$ & $177(81.6)$ \\
Japanese traditional massage and finger pressure & & \\
Current & $6(5.9)$ & $19(8.4)$ \\
Ever & $10(9.9)$ & $43(18.9)$ \\
Never & $85(84.2)$ & $165(72.7)$ \\
\hline
\end{tabular}

CAM: complementary and alternative medicine.

Data are shown as a percentage in parentheses.

Lifetime prevalence of CAM therapies was defined as the proportion of total current and ever user in the surveyed population. 
The lifetime prevalence of Japanese traditional massage and finger pressure, chiropractic and seitai use was similar to that of acupuncture and moxibustion. Moreover, the lifetime prevalence of manual therapy such as chiropractic and massage was $30 \%$ in Sweden ${ }^{22)}, 13.1 \%$ in the $\mathrm{UK}^{7)}, 13 \%$ in Norway ${ }^{22)}, 4.9 \%$ in Malaysia ${ }^{27)}$ and 3.3\% in Ireland ${ }^{28)}$, respectively. However, the lifetime prevalence was not well reported in Japan. Last 12-month prevalence of chiropractic or massage that was reported in 2 systematic reviews ranged from 1.5 to $16.2 \%{ }^{29)}$ and 0.04 to $17.8 \%{ }^{24)}$. Last 12 -month prevalence of "chiropractic or osteopathy" and "massage or acupressure" among the Japanese population was 5.9\% and 14.1\%, respectively 26 ). Prevalence of Japanese traditional massage and finger pressure is perhaps similar to that of manual therapies in Europe.

The present study has several strengths. First, a high response rate was obtained because of the cooperative attitude from the beginning among participants in a given city. Second, community-dwelling older people were the focus in our study. Most previous studies on a Japanese population were hospital-based $\left.{ }^{21}, 30\right)$. However, several limitations must be considered. First, data were obtained from self-reports, which involved recall bias. Second, information on CAM therapies was obtained using an original questionnaire. Although the International CAM Questionnaire was developed to measure use of CAM therapies $^{31)}$, it does not include Judo therapy and Japanese traditional massage and finger pressure.

In conclusion, the lifetime prevalence of Judo therapy use was $28.0 \%$ and $45.4 \%$ among males and females, respectively; that of acupuncture and moxibustion use was $17.8 \%$ and $18.4 \%$ among males and females, respectively, while that of Japanese traditional massage and finger pressure use was $15.8 \%$ and $27.3 \%$ among males and females, respectively. These results showed that not only Western medicine but also these 3 CAM therapies were common among community-dwelling older people in Japan.

\section{Funding}

This research was a part of the survey entitled "Questionnaire survey on the relationship between social participation and health status among active older people", and supported by the grant from "Fujinokuni-consortium" (grant number: 40).

\section{Conflict of interest}

None.

\section{REFERENCES}

1) World Health Organization: Legal status of traditional medicine and complementary/alternative medicine: a worldwide review. http://apps.who.int/medicinedocs/pdf/h2943e/h2943e.pdf (Accessed Feb. 7, 2020)

2) Suganya M, Vikneshan M, Swathy U: Usage of complementary and alternative medicine: a survey among Indian dental professionals. Complement Ther Clin Pract, 2017, 26: 26-29. [Medline] [CrossRef]

3) Baek SM, Choi SM, Seo HJ, et al.: Use of complementary and alternative medicine by self- or non-institutional therapists in South Korea: a community-based survey. Integr Med Res, 2013, 2: 25-31. [Medline] [CrossRef]

4) Eisenberg DM, Davis RB, Ettner SL, et al.: Trends in alternative medicine use in the United States, 1990-1997: results of a follow-up national survey. JAMA, 1998, 280: 1569-1575. [Medline] [CrossRef]

5) Falci L, Shi Z, Greenlee H: Multiple chronic conditions and use of complementary and alternative medicine among US adults: results from the 2012 national health interview survey. Prev Chronic Dis, 2016, 13: E61. [Medline] [CrossRef]

6) Gerber LM, Mamtani R, Chiu YL, et al.: Use of complementary and alternative medicine among midlife Arab women living in Qatar. East Mediterr Health J, 2014, 20: 554-560. [Medline] [CrossRef]

7) Hunt KJ, Coelho HF, Wider B, et al.: Complementary and alternative medicine use in England: results from a national survey. Int J Clin Pract, 2010, 64: 1496-1502. [Medline] [CrossRef]

8) Ness J, Cirillo DJ, Weir DR, et al.: Use of complementary medicine in older Americans: results from the Health and Retirement Study. Gerontologist, 2005, 45: 516-524. [Medline] [CrossRef]

9) Ock SM, Choi JY, Cha YS, et al.: The use of complementary and alternative medicine in a general population in South Korea: results from a national survey in 2006. J Korean Med Sci, 2009, 24: 1-6. [Medline] [CrossRef]

10) Torres-Zeno RE, Ríos-Motta R, Rodríguez-Sánchez Y, et al.: Use of complementary and alternative medicine in Bayamon, Puerto Rico. P R Health Sci J, 2016, 35: 69-75. [Medline]

11) Xue CC, Zhang AL, Lin V, et al.: Acupuncture, chiropractic and osteopathy use in Australia: a national population survey. BMC Public Health, 2008, 8: 105. [Medline] [CrossRef]

12) National Center for Complementary and Integrative Health: Complementary, alternative, or integrative health: what's in a name? https://nccih.nih.gov/health/ integrative-health (Accessed Feb. 7, 2020)

13) Ministry of Health Labour and Welfare: Report on Public Health Administration and Services (practicing health professionals) 2014. https://www.mhlw.go.jp/ english/database/db-hss/dl/rophas_2014_biennialyear.pdf(Accessed Feb. 7, 2020)

14) Ishizaki N, Yano T, Kawakita K: Public status and prevalence of acupuncture in Japan. Evid Based Complement Alternat Med, 2010, 7: 493-500. [Medline] [CrossRef]

15) Togo T, Urata S, Sawazaki K, et al.: Demand for CAM practice at hospitals in Japan: a population survey in Mie prefecture. Evid Based Complement Alternat Med, 2011, 2011: 591868. [Medline] [CrossRef]

16) Donoyama N, Munakata T, Shibasaki M: Effects of Anma therapy (traditional Japanese massage) on body and mind. J Bodyw Mov Ther, 2010, 14: 55-64. 
[Medline] [CrossRef]

17) Ministry of Health Labour and Welfare: Estimates of National Medical Care Expenditure 2017. https://www.mhlw.go.jp/english/database/db-hss/dl/digest2017. pdf (Accessed Feb. 7, 2020)

18) Inoue S, Nakao M, Nomura K, et al.: Increased number of judo therapy facilities in Japan and changes in their geographical distribution. BMC Health Serv Res, 2011, 11: 48. [Medline] [CrossRef]

19) Inoue S, Karita K, Yano E: Geographical distribution of judo therapists and orthopedists in Japan. J Manipulative Physiol Ther, 2005, 28: 253-258. [Medline] [CrossRef]

20) Nishikitani M, Inoue S, Yano E: Competition or complement: relationship between judo therapists and physicians for elderly patients with musculoskeletal disease. Environ Health Prev Med, 2008, 13: 123-129. [Medline] [CrossRef]

21) Shumer G, Warber S, Motohara S, et al.: Complementary and alternative medicine use by visitors to rural Japanese family medicine clinics: results from the international complementary and alternative medicine survey. BMC Complement Altern Med, 2014, 14: 360. [Medline] [CrossRef]

22) Hanssen B, Grimsgaard S, Launsø L, et al.: Use of complementary and alternative medicine in the Scandinavian countries. Scand J Prim Health Care, 2005, 23: 57-62. [Medline] [CrossRef]

23) Thomas KJ, Nicholl JP, Coleman P: Use and expenditure on complementary medicine in England: a population based survey. Complement Ther Med, 2001, 9 : 2-11. [Medline] [CrossRef]

24) Cooper KL, Harris PE, Relton C, et al.: Prevalence of visits to five types of complementary and alternative medicine practitioners by the general population: a systematic review. Complement Ther Clin Pract, 2013, 19: 214-220. [Medline] [CrossRef]

25) Harris PE, Cooper KL, Relton C, et al.: Prevalence of complementary and alternative medicine (CAM) use by the general population: a systematic review and update. Int J Clin Pract, 2012, 66: 924-939. [Medline] [CrossRef]

26) Yamashita H, Tsukayama H, Sugishita C: Popularity of complementary and alternative medicine in Japan: a telephone survey. Complement Ther Med, 2002, 10: 84-93. [Medline] [CrossRef]

27) Siti ZM, Tahir A, Farah AI, et al.: Use of traditional and complementary medicine in Malaysia: a baseline study. Complement Ther Med, 2009, 17: 292-299. [Medline] [CrossRef]

28) Fox P, Coughlan B, Butler M, et al.: Complementary alternative medicine (CAM) use in Ireland: a secondary analysis of SLAN data. Complement Ther Med, 2010, 18: 95-103. [Medline] [CrossRef]

29) Harris PE, Cooper KL, Relton C, et al.: Prevalence of visits to massage therapists by the general population: a systematic review. Complement Ther Clin Pract, 2014, 20: 16-20. [Medline] [CrossRef]

30) Uchida K, Inoue M, Otake K, et al.: Complementary and alternative medicine use by Japanese children with pediatric surgical diseases. Open J Pediatr, 2013, 3: 32439. [CrossRef]

31) Quandt SA, Verhoef MJ, Arcury TA, et al.: Development of an international questionnaire to measure use of complementary and alternative medicine (I-CAMQ). J Altern Complement Med, 2009, 15: 331-339. [Medline] [CrossRef] 